\title{
A Simplified Morphing Blade for Horizontal Axis Wind Turbines
}

\author{
Weijun WANG, Stéphane CARO, Fouad BENNIS \\ Institut de Recherche en Communications \\ et Cybernétique de Nantes \\ 1 rue de la Noë, 44321 Nantes, France \\ Email: \{weijun.wang, stephane.caro, fouad.bennis\} \\ @irccyn.ec-nantes.fr \\ Oscar Roberto SALINAS MEJIA \\ Instituto Tecnologico y \\ de Estudios Superiores de Monterrey \\ Chihuahua, Ch., Mexico \\ Email: oscar_roberto_salinas@hotmail.com
}

\begin{abstract}
The aim of designing wind turbine blades is to improve the power capture ability. Since rotor control technology is currently limited to controlling rotational speed and blade pitch, an increasing concern has been given to morphing blades. In this paper, a simplified morphing blade is introduced, which has a linear twist distribution along the span and a shape that can be controlled by adjusting the twist of the blade's root and tip. To evaluate the performance of wind turbine blades, a numerical code based on the blade element momentum theory is developed and validated. The blade of the NREL Phase VI wind turbine is taken as a reference blade and has a fixed pitch. The optimization problems associated with the control of the morphing blade and a blade with pitch control are formulated. The optimal results show that the morphing blade gives better results than the blade with pitch control in terms of produced power. Under the assumption that at a given site, the annual average wind speed is known and the wind speed follows a Rayleigh distribution, the annual energy production of wind turbines was evaluated for three types of blade, namely, morphing blade, blade with pitch control and fixed pitch blade. For an annual average wind speed varying between $5 \mathrm{~m} / \mathrm{s}$ and $15 \mathrm{~m} / \mathrm{s}$, it turns out that the annual energy production of the wind turbine containing morphing blades is $24.5 \%$ to $69.7 \%$ higher than the annual energy production of the wind turbine containing pitch fixed blades. Likewise, the annual energy production of the wind turbine containing blades with pitch control is $22.7 \%$ to $66.9 \%$ higher than the annual energy production of the wind turbine containing pitch fixed blades.
\end{abstract}

\section{Nomenclature}

$C_{p} \quad$ Power coefficient of wind turbine rotor
$C_{T}$ Thrust coefficient of wind turbine rotor

$v$ Wind speed

$v_{0} \quad$ Free stream wind speed

$v_{r} \quad$ Relative wind speed

$v_{r e}$ Reference wind speed

$v_{c i} \quad$ Cut-in wind speed

$v_{c o} \quad$ Cut-out wind speed

$v_{\text {rated }}$ Rated wind speed of wind turbine

$\bar{v} \quad$ Average wind speed

$p(v)$ Probability for the wind speed to be equal to $v$

a Axial induction factor at rotor plane

$a^{\prime}$ Angular induction factor

$b$ Number of blades of a rotor

$N$ Number of blade elements

$\rho$ Air density

$P$ Produced Power of wind turbine rotor

$P_{\text {rated }}$ Rated Produced Power of wind turbine rotor

$\mathbf{x}$ Vector of the decision variables

p Vector of the design parameters

$r$ Radial coordinate at rotor plane

$r_{t}$ Tip Radius of the blade

$r_{r}$ Root radius of the blade

$r_{i} \quad$ Blade radius for the $i$ th element

$F_{D} \quad$ Drag force on an annular blade element

$F_{L} \quad$ Lift force on an annular blade element

$F_{a} \quad$ The axial force on the blade element

$F_{t}$ The edgewise forces on the blade element

$T_{t} \quad$ Rotor torque

$C_{D} \quad$ Drag coefficient of an airfoil

$C_{L} \quad$ Lift coefficient of an airfoil

$F \quad$ Tip-loss factor

$\omega$ Rotor rotational speed

c Blade chord length 
c Vector of the blade chord lengths

$\alpha$ Angle of attack

$\beta$ Pitch control angle

$\beta_{0} \quad$ Fixed pitch angle

$\phi$ Angle of relative wind speed with rotor plane

$\gamma$ Twist angle

$\gamma_{i} \quad$ Actual twist angle for the $i$ th blade element

$\gamma_{i 0} \quad$ Pre-twist angle for the $i$ th blade element

$\gamma_{t} \quad$ Twist angle for the tip of the blade

$\gamma_{r}$ Twist angle for the root of the blade

$\boldsymbol{\gamma}$ Vector of the blade twist angles

$\sigma$ Solidity ratio

$k$ Shape factor of Weibull distribution

WT Wind Turbine

HAWT Horizontal-Axis Wind Turbine

BEMT Blade Element Momentum Theory

FPB Fixed Pitch Blade

BPC Blade with Pitch Control

MB Morphing Blade

AEP Annual Energy Production

OSU Ohio State University

\section{Introduction}

Wind energy is growing more and more popular worldwide. The search for ways to make wind turbines (WT) more efficient and competitive becomes paramount. The main control methods used to optimize or limit the power extracted from the wind turbine are usually based on the control of the rotor's rotational speed and the pitch of the blades. Recently, an increasing concern has been given to Morphing Blades (MB) [1-3].

It is well known that MB can improve the power efficiency by changing their shape according to variations in wind speed. Moreover, they have the potential to significantly relieve unwanted stresses in the blades to prolong their life while the wind is very harsh on them. Barlas et al. [4] presented status of active aero-elastic rotor control research for wind turbines in terms of using advanced control concepts to reduce loads on the rotor. They analyzed the smart control concepts, including twist control, camber control and moveable control surfaces (trailing edge flaps or servo tabs actuated by smart materials). In the scope of this study, the term "morphing blade" means that the angle of attack of each section of the blade is controlled rather than the aerodynamic characteristic curve of the section.

MBs can be either "passive" or "active" depending on the type of twist control. The former are essentially monolithic and rely on the flexibility of their structure or, in other words, on elastic deformation. In contrast, "active adaptive blades" are made up of a number of independent span-wise sections that can be oriented to achieve any desired twist distribution. Although the adaptation of the blade shape has the ability to optimize the efficiency, due to the complex structure and high cost, its application has been limited. In this paper, a simplified MB is introduced. This morphing blade has a linear twist distribution along the span.
Since the combined Blade Element Momentum Theory (BEMT) is a fairly accurate analytical tool and has low computational cost, it is widely used in the wind energy industry to estimate the theoretical output power from a rotor with defined blade dimensions [5-9]. A numerical code is developed in this paper based on the BEMT and validated by comparison with the experimental results of the NREL phase VI test turbine $[10,11]$, which is a stall-controlled wind turbine.

This turbine is regulated using passive stall methods at high wind speeds to limit the output power. Thus, there is great potential for improvement of its power capture capability. Here, we use the blade of the NREL Phase VI WT as a reference blade, and formulate the optimization problem associated with the proposed simplified MB. To make a good comparison, the optimization problem associated with the blade with pitch control (BPC) is also formulated. The optimal results show that the $\mathrm{MB}$ gives better results than the BPC in terms of produced power. Under the assumption that in a given site, the annual average wind speed is known and the wind speed follows a Rayleigh distribution, we can evaluate the annual energy produced by these three types of blade.

The paper is organized as follows. The BEMT is presented in Sec. 2. The calculation model used to evaluate the WT produced power is described in Sec. 3. The proposed simplified MB is introduced in Sec. 4. Some optimization problems are formulated in Sec. 5 for the control of the wind turbines. Optimal results are also given. Finally, some concluding remarks and future work are provided in Sec. 6.

\section{Blade Element Momentum Theory \\ 2.1 Momentum Theory}

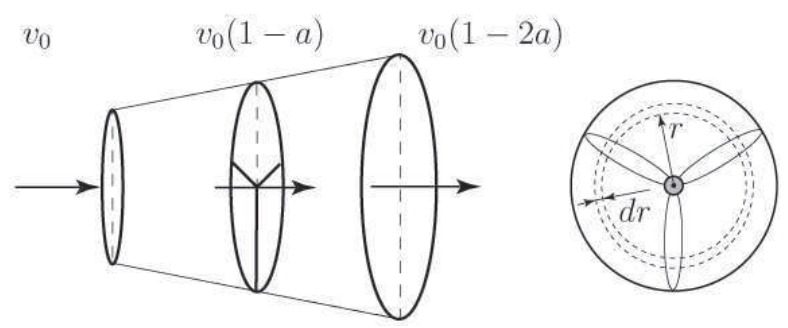

Fig. 1: Schematic of momentum theory for wind turbines

Figure 1 gives a schematic of the momentum theory for wind turbines. Based on some assumptions, a simple model, known as actuator disc model, can be used to determine the power from an ideal turbine rotor and the thrust of the wind on the ideal rotor $[5,7]$. From axial momentum and angular momentum, the element of thrust $d F_{a}$ and the element of torque $d T_{t}$ can be obtained as:

$$
\begin{aligned}
& d F_{a}=4 \pi \rho v_{0}^{2} a(1-a) r d r \\
& d T_{t}=4 \pi \rho v_{0} \omega a^{\prime}(1-a) r^{3} d r
\end{aligned}
$$




\subsection{Blade Element Theory}

In order to apply blade element analysis, it is assumed that the blade is divided into $N$ sections. The analysis is based on some assumptions, such as that there is no aerodynamic interaction between different blade elements and the forces on the blade elements are solely determined by the lift and drag coefficients $[5,7,12]$.

Figure 2 shows the velocities and forces on a blade element of a wind turbine blade. As a result, the following equations are obtained:

$$
\begin{aligned}
\phi & =\arctan \frac{v_{0}(1-a)}{\omega r\left(1+a^{\prime}\right)} \\
v_{r} & =\frac{v_{0}(1-a)}{\sin \phi} \\
\alpha & =\phi-\gamma
\end{aligned}
$$

Lift and drag forces on an annular blade element are given by:

$$
\begin{aligned}
d F_{L} & =\frac{\rho c}{2} v_{r}^{2} C_{L} d r \\
d F_{D} & =\frac{\rho c}{2} v_{r}^{2} C_{D} d r
\end{aligned}
$$

These lift coefficient $C_{L}$ and drag coefficient $C_{D}$ depend on the angle of attack $\alpha$ and the blade profile. The element of thrust $d F_{a}$ and the element of torque $d T_{t}$ are expressed as:

$$
\begin{aligned}
d F_{a} & =b \frac{\rho c}{2} v_{r}^{2}\left(C_{L} \cos \phi+C_{D} \sin \phi\right) d r \\
d T_{t}=r d F_{t} & =b \frac{\rho c}{2} v_{r}^{2}\left(C_{L} \sin \phi-C_{D} \cos \phi\right) r d r
\end{aligned}
$$

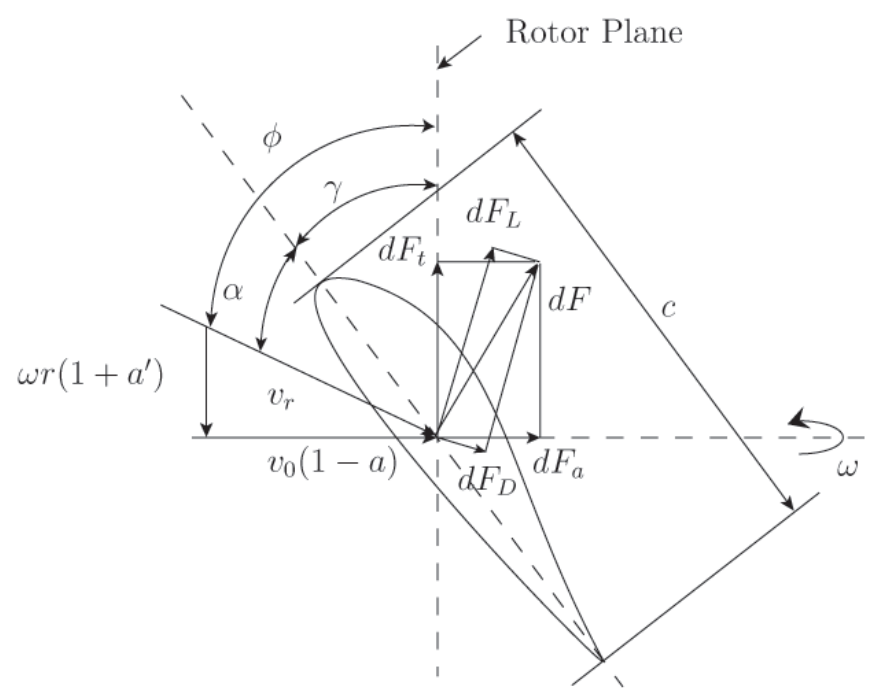

Fig. 2: Velocities and forces on a blade element

\subsection{Blade Element Momentum Theory}

By combining Eqn. (1) and Eqn. (8), Eqn. (2) and Eqn. (9):

$$
\begin{aligned}
4 \pi \rho v_{0}^{2} a(1-a) r d r & =b \frac{\rho c}{2} v_{r}^{2}\left(C_{L} \cos \phi+C_{D} \sin \phi\right) d r(10) \\
4 \pi \rho v_{0} \omega a^{\prime}(1-a) r^{3} d r & =b \frac{\rho c}{2} v_{r}^{2}\left(C_{L} \sin \phi-C_{D} \cos \phi\right) d r(11)
\end{aligned}
$$

After some algebraic manipulations and by adding the correction of the Prandtl tip loss factor, the following relationships are obtained [6]:

$$
\begin{aligned}
& a=\frac{1}{\frac{4 F \sin ^{2} \phi}{\sigma\left(C_{L} \cos \phi+C_{D} \sin \phi\right)}+1} \\
& a^{\prime}=\frac{1}{\frac{4 F \sin \phi \cos \phi}{\sigma\left(C_{L} \sin \phi-C_{D} \cos \phi\right)}+1}
\end{aligned}
$$

where $F$ is the Prandtl tip loss factor defined as:

$$
F=\frac{1}{\pi} \arccos \left[\exp \left(\frac{b\left(r-r_{t}\right)}{2 r \sin \phi}\right)\right]
$$

and $\sigma$ is the rotor solidity, defined as:

$$
\sigma=\frac{c b}{2 \pi r}
$$

It is to be noted that Eqn. (12) is valid for the axial induction factor value to be between 0 and 0.4 . For axial induction factor greater than 0.4 , there are several methods to obtain it $[6,9,13,14]$. In this paper, we use the method proposed by Buhl [13] and implemented by R. Lanzafame [6], namely

$$
a=\frac{18 F-20-3 \sqrt{C_{T}(50-36 F)+12 F(3 F-4)}}{36 F-50}
$$

where $C_{T}$ is the thrust coefficient of the wind turbine rotor. For each blade element, it can be calculated as [5]:

$$
C_{T}=\frac{d F_{a}}{1 / 2 \rho v_{0}^{2} 2 \pi r d r}=\frac{\sigma(1-a)^{2}\left(C_{L} \cos \phi+C_{D} \sin \phi\right)}{\sin ^{2} \phi}
$$

\section{Calculation Model}

\subsection{Model Formulation}

One of the most difficult issues for BEMT is to determine the induction factors ( $a$ and $a^{\prime}$ ) and the correct lift and drag coefficients $\left(C_{L}\right.$ and $\left.C_{D}\right)$.

Here, we determine the induction factors by using an iteration method, which is currently the governing method 
$[5,7,9]$. Figure 3 shows the flowchart to determine the induction factors $a$ and $a^{\prime}$. The parameters associated with each section are given, namely, the chord length $c$, the twist angle $\gamma$, the free stream wind speed $v_{0}$, the air density $\rho$, the radial coordinate at rotor plane $r$, the root radius $r_{t}$ of the wind turbine, the rotor rotational speed $\omega$, the number of blades $b$, they airfoil type and its aerodynamic parameters.

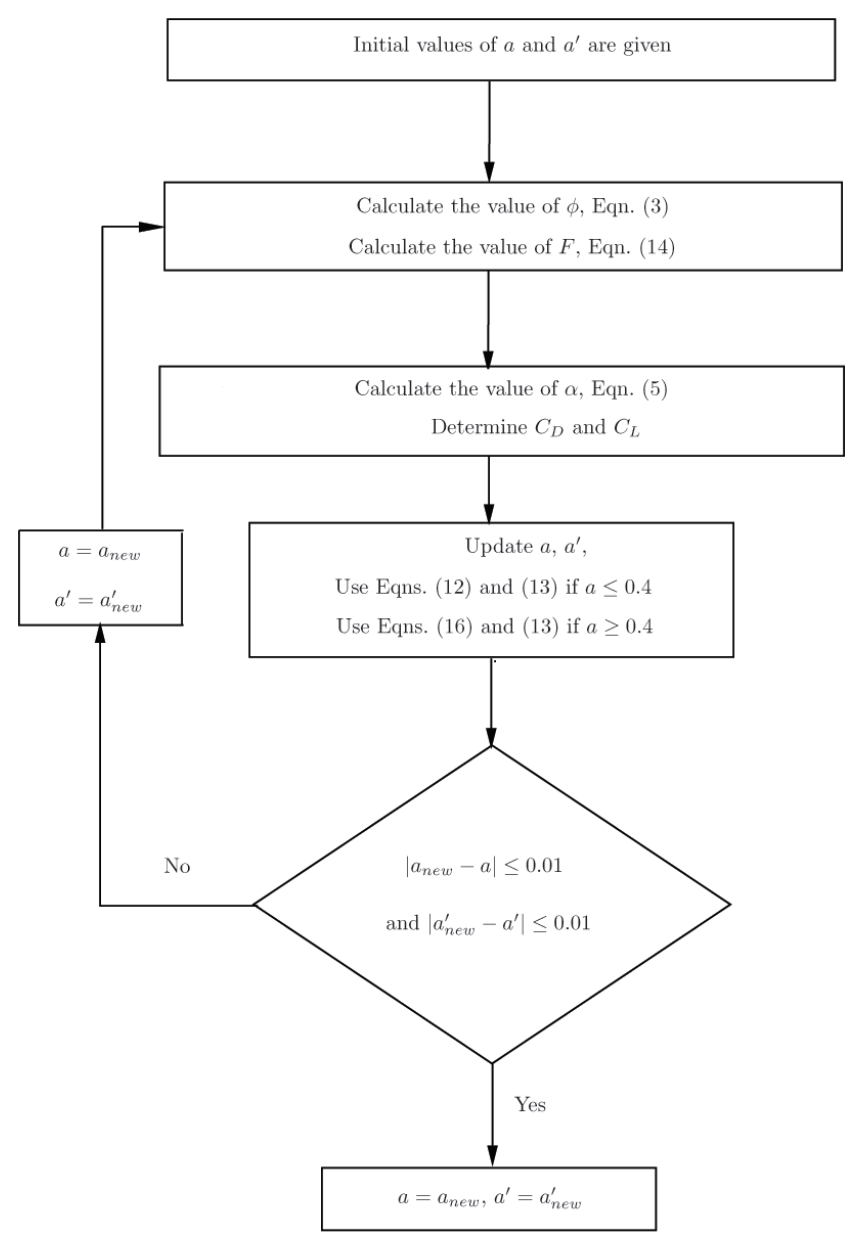

Fig. 3: Calculation flowchart for induction factors

In order to find a piecewise polynomial relation between $\alpha$ and $C_{D}$ ( $\alpha$ and $C_{L}$, respectively) from the experimental data, R. Lanzafame implemented a fifth-order logarithmic polynomial for the angle of attack from $-6^{\circ}$ to $20^{\circ}$. For the angle of attack from $20^{\circ}$ to $45^{\circ}$, the mathematical functions of the following equations were implemented [6]:

$$
\begin{aligned}
& C_{L}=2 C_{L_{\text {max }}} \sin \alpha \cos \alpha \\
& C_{D}=2 C_{D_{\text {max }}} \sin ^{2} \alpha
\end{aligned}
$$

The $C_{L_{\max }}$ and $C_{D_{\max }}$ are shown as follows:

$$
C_{L_{\max }}=\left.C_{L}\right|_{\alpha=45^{\circ}} \text { and } C_{D_{\max }}=\left.C_{D}\right|_{\alpha=90^{\circ}}
$$

In this work, a cubic spline interpolation was implemented for the angle of attack from $-20^{\circ}$ to $20^{\circ}$, and the mathematical functions in Eqn. (18) and Eqn. (19) were implemented for the angle of attack from $20^{\circ}$ to $90^{\circ}$.

The experimental data for a two-dimensional S809 airfoil section were obtained obtained at the OSU (Ohio State University) wind tunnel with a Reynolds number from 990,000 to $1,040,000[10,15,16]$. Figure 4 shows $C_{D}$ as a function of $\alpha$ and $C_{L}$ as a function of $\alpha$. This figure also provides a comparison of the functions from the fifth-order logarithmic polynomial and that from the cubic spline interpolation.
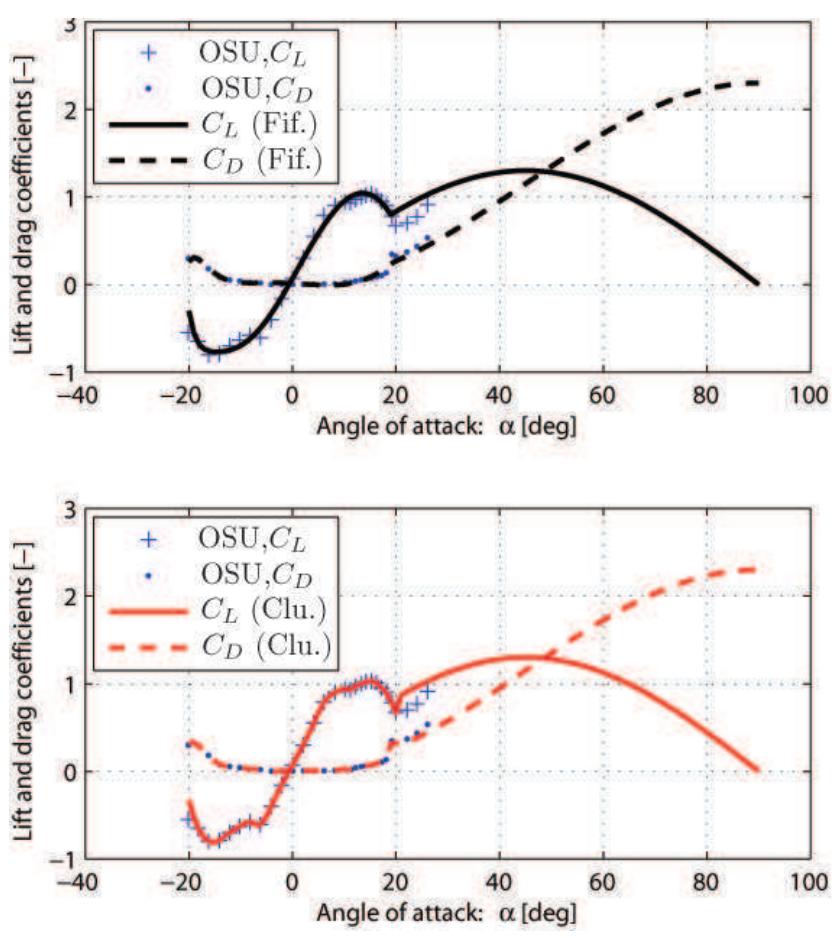

Fig. 4: $C_{D}$ and $C_{L}$ as a function of $\alpha$ for $\mathrm{S} 809$ airfoil

After obtaining the induction factors $a$ and $a^{\prime}$ for each section, the thrust force and the driving force on the complete turbine can be calculated by using Eqn. (21) and Eqn. (22):

$$
\begin{gathered}
F_{a}=\sum_{j=1}^{b} \int_{r_{r}}^{r_{t}} d F_{a} \\
T_{t}=\sum_{j=1}^{b} \int_{r_{r}}^{r_{t}} d T_{t}
\end{gathered}
$$

Then the produced power $P$ and the power coefficient $C_{p}$ of a wind turbine rotor are expressed as follows:

$$
\begin{aligned}
P & =T_{t} \omega \\
C_{p} & =\frac{P}{\frac{1}{2} \rho \pi r_{t}^{2} v_{0}^{3}}
\end{aligned}
$$




\subsection{Validation of the Model}

To verify the validity of the formulated calculation model, we take the NERL Phase VI WT as an example. This wind turbine has two twisted blades, a variable chord along the blade, and a rotor of diameter equal to $10 \mathrm{~m}$. The blade section is of type S809. The rotational speed of the rotor is constant and equal to $72 \mathrm{rpm}$ with a rated produced power equal to $19.8 \mathrm{~kW}[10,11]$.

In accordance with experiments, the angle between the rotor plane and the tip chord is constant and equal to $3 \mathrm{deg}$. Therefore, we end up with a Fixed Pitch Blade (FPB) and the fixed pitch angle is equal to $4.775 \mathrm{deg}$. Figure 5 shows the distribution of the actual twist and chord distribution of the FPB.

In the calculation model, the root radius $r_{r}$ and tip radius $r_{t}$ of the blade are equal to $1.27 \mathrm{~m}$ and $5 \mathrm{~m}$, respectively. The blade is divided into 18 cross-sections. The air density $\rho$ is equal to $1.25 \mathrm{~kg} / \mathrm{m}^{3}$ and the reference wind speed varies $5 \mathrm{~m} / \mathrm{s}$ and $25 \mathrm{~m} / \mathrm{s}$. In order to make a better comparison, in Fig. 6 we also provide the obtained simulation results of the calculation model representing the lift and drag coefficients based on a fifth-order logarithmic polynomial (the angle of attack from $-20^{\circ}$ to $20^{\circ}$ ). Figure 6 shows a good agreement between simulated and experimental results.
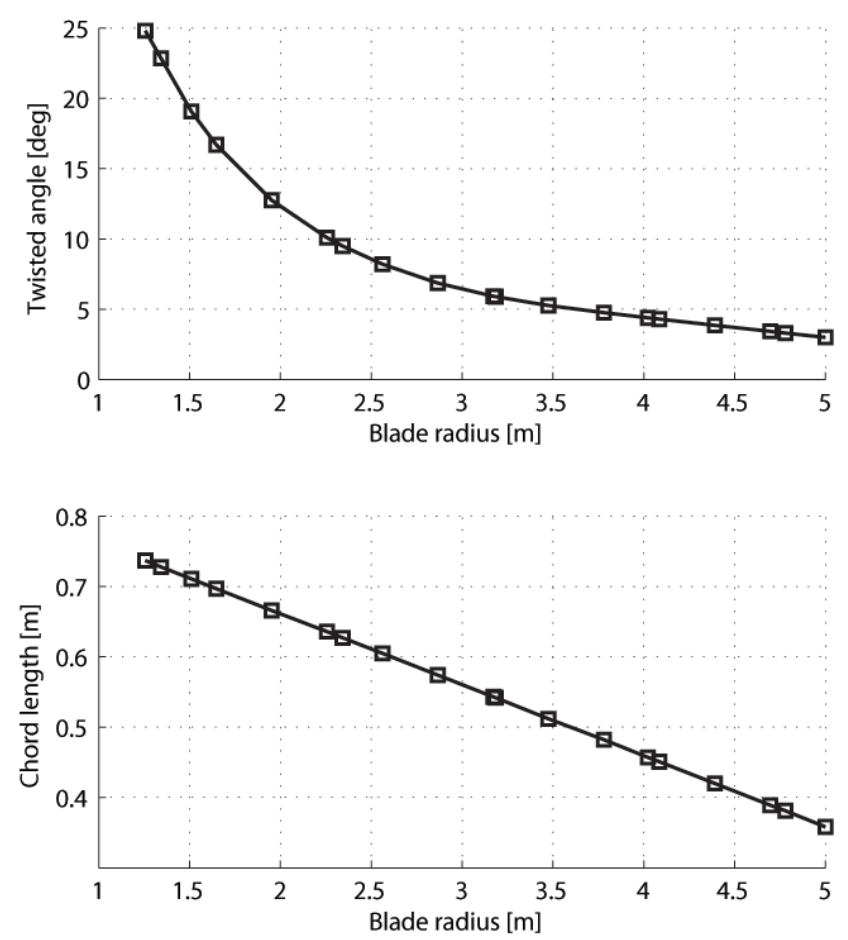

Fig. 5: Twist and chord distributions of Phase VI WT blades
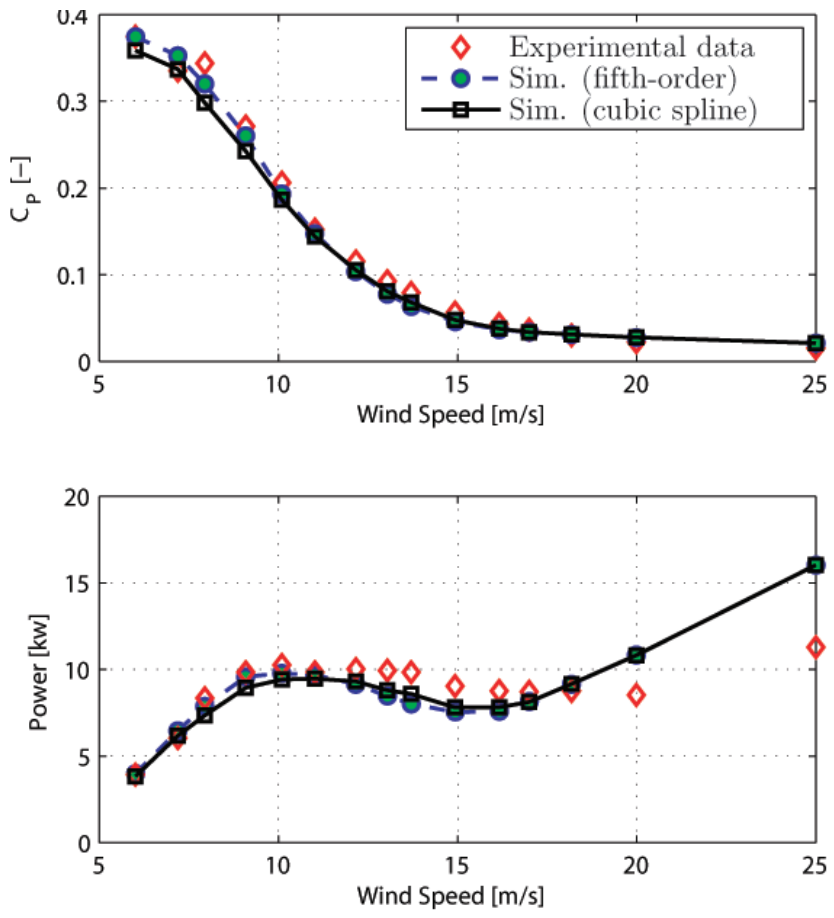

Fig. 6: Comparison between simulated and experimental results

\section{The Simplified Morphing Blade \\ 4.1 Wind Speed Regimes}

Usually, the well controlled WTs operate in two primary regimes [17], namely, the partial load region and the full load region, as shown in Fig. 7. The cut-in wind speed $v_{c i}$ is the minimum wind speed at which the WT generates usable power and the cut-out wind speed $v_{c o}$ is the one at which the braking system is activated to slow down or stop the turbine in order to avoid any damage.

Meanwhile, to protect the components of the WT, wind power must be shed to limit output power when wind speed is over the rated speed. The partial load region where wind speed varies between cut-in speed $v_{c i}$ and rated speed $v_{\text {rated }}$ is named "Region 1". The full load region where wind speed varies between rated speed $v_{\text {rated }}$ and cut-out speed $v_{c o}$ is named "Region 2".

\subsection{The Fixed Pitch Blade}

It is well known that due to geometric reasons, the effective wind velocity vector varies both, in magnitude and direction, along a wind turbine blade. An optimum performance - assuming constant airfoil section throughout the blade - would require the exact same relative orientation between the local wind velocity vector and the corresponding cross-section of the blade. As an attempt to reach s-uch optimum performance, modern blades are produced with a physical twist, which may correspond to the theoretically ideal value.

A Fixed Pitch Blade (FPB) operates at a fixed pitch angle. For a FPB, the actual twist angle $\gamma_{i}$ of the $i$ th blade ele- 


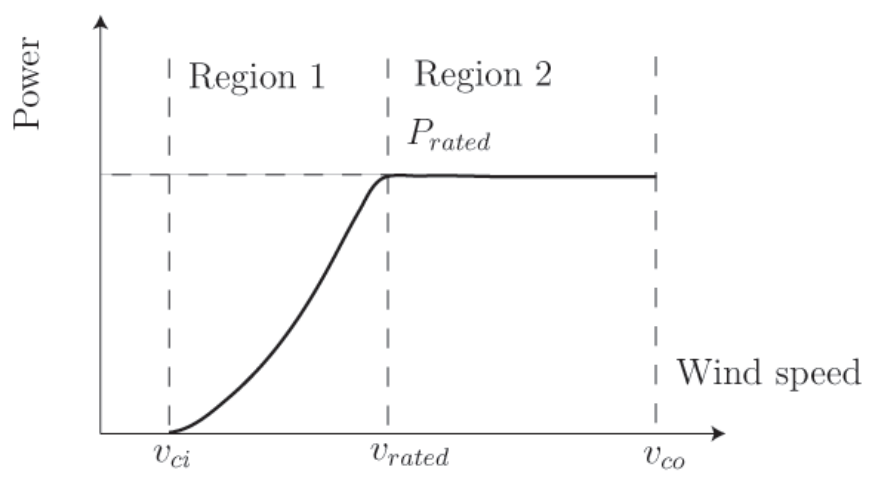

Fig. 7: Produced power as a function of wind speed

ment is the sum of its pre-twist angle $\gamma_{i 0}$ and the fixed pitch angle $\beta_{0}$, namely,

$$
\gamma_{i}=\gamma_{i 0}+\beta_{0}
$$

\subsection{The Blade with Pitch Control}

A Blade with Pitch Control (BPC) implies that the pitch of the WT's rotor blades can be adjusted by a pitch control system. An optimal design is needed to pitch the rotor blades in order to maximize the produced power at any wind speed. In Region 1, pitch control can improve the power coefficient. In Region 2, pitch control can maintain a constant output power, $P_{\text {rated }}$.

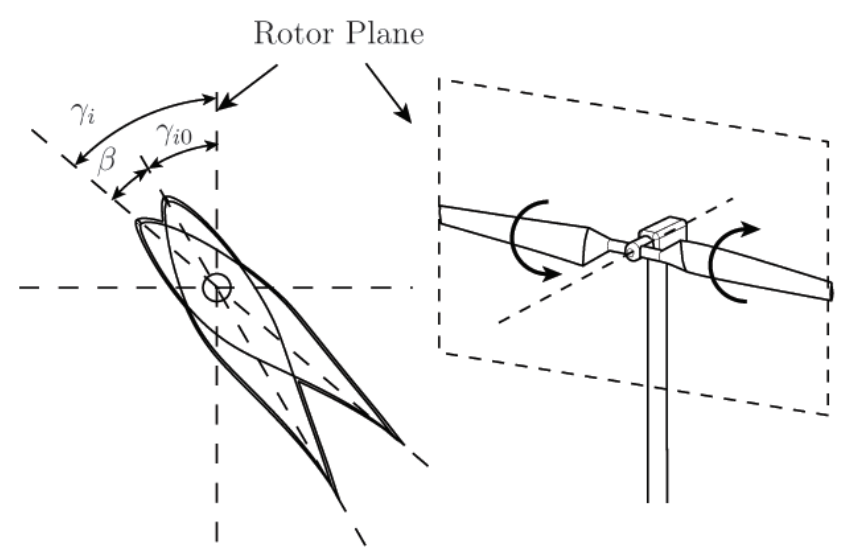

Fig. 8: Schematic of a blade with pitch control

Figure 8 shows the schematic of a BPC. Since the pitch control system can not change the shape of the blades, any adjustment will result in all blades sections experiencing the same change in actual twist angle. For a twisted blade, the actual twist angle of the $i$ th element is the sum of the pretwist angle and the pitch control angle, $\beta$ :

$$
\gamma_{i}=\gamma_{i 0}+\beta
$$

\subsection{The Simplified Morphing Blades}

A morphing blade has the ability to approach the optimal profile and especially the optimal angle of attack for each element. This aim can be achieved in an active or passive manner.

Figure 9 shows a MB with active control. This blade has a constant airfoil section throughout the blade and the twist angle of each element can be controlled by some mechanisms, to correspond to the theoretically ideal value. It is apparent that the mechanisms used to control the elements individually may be complex and expensive.

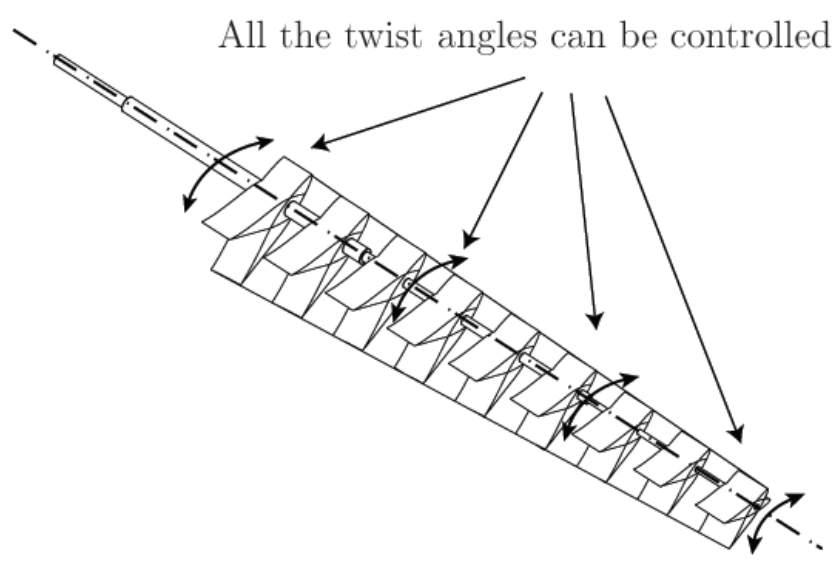

Fig. 9: Schematic of a morphing blade with active control

Here, a simplified MB is introduced, as shown in Fig. 10. We set two twist control mechanisms, at the first element and at the last element. The twist angle of the other elements is adjusted automatically. Once end values are set, the twist angle distribution becomes linear along the blade. When the two twist angles, at the first element and at the last element, $\gamma_{r}$ and $\gamma_{t}$ are given, the actual twist angle for the $i$ th blade element is calculated with Eqn. (27).

$$
\gamma_{i}=\left(\gamma_{r}-\gamma_{t}\right) \frac{r_{i}-r_{t}}{r_{r}-r_{t}}+\gamma_{t}
$$

It is noteworthy that the conventional blade has a fixed shape and a hollow profile usually formed by two shell structures and some webs, as shown in Fig. 11. For MB, since the shape of the blade is changeable, the blade must be divided into several elements and there must be a flexible skin along the span.

\section{Optimization Problems and Result Analysis 5.1 Optimization Problem for the Simplified Morphing Blade}

The Phase VI WT is taken as a reference $[10,11]$. The simplified morphing blade is divided into 18 cross-sections. The objective is to maximize the output power $P$ at a steady wind speed. 


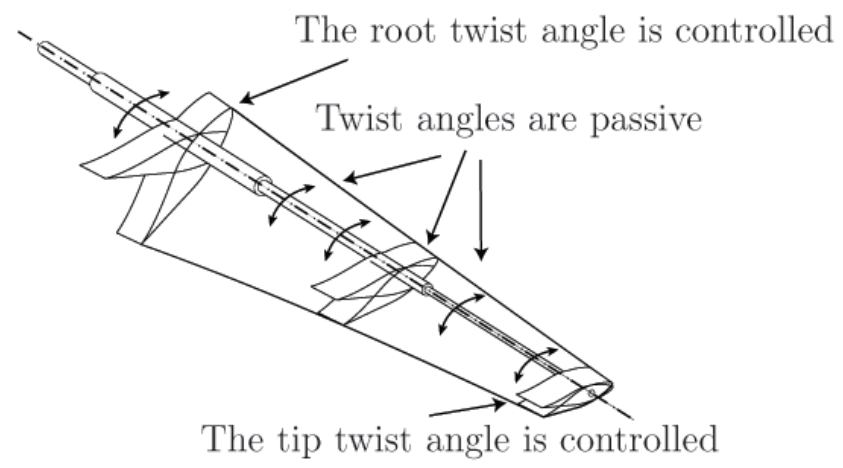

Fig. 10: Schematic of a simplified morphing blade

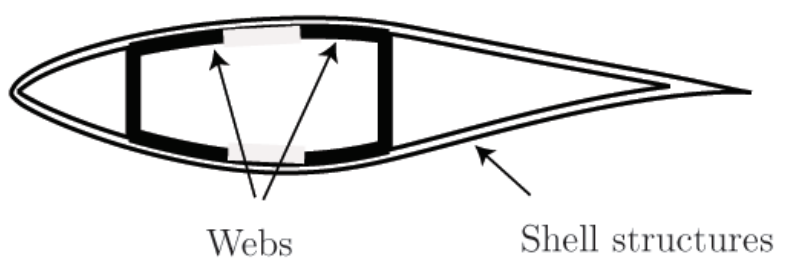

Fig. 11: Section of a conventional blade showing upper and lower shells and webs

Table 1: Design parameters

\begin{tabular}{cc}
\hline \hline Parameter & Value \\
\hline Number of blades b & 2 \\
Chord distribution c & see Fig. 5 \\
Section airfoils & S809, see Sec. 3 \\
Radius of rotor $r_{t}(\mathrm{~m})$ & 5 \\
Root length $r_{r}(\mathrm{~m})$ & 1.27 \\
Rotor rotational speed $\omega(\mathrm{rpm})$ & 72 \\
Air density $\rho\left(\mathrm{kg} / \mathrm{m}^{3}\right)$ & 1.25 \\
Cut-in wind speed $v_{c i}(\mathrm{~m} / \mathrm{s})$ & 5 \\
Cut-out wind speed $v_{c o}(\mathrm{~m} / \mathrm{s})$ & 25 \\
\hline \hline
\end{tabular}

For the simplified morphing blade, the two twist angles at the first element and at the last element, $\gamma_{r}$ and $\gamma_{t}$ are decision variables. Then the actual twist angle of the $i$ th blade element can be calculated as Eqn. (27). The lower and upper bounds of the decision variables $\mathbf{x}$ are: $0 \mathrm{deg} \leq \gamma_{r} \leq 35 \mathrm{deg}$ and $-5 \mathrm{deg} \leq \gamma_{t} \leq 15 \mathrm{deg}$.

$\mathbf{p}$ is the set of design parameters given in Table 1. The only constraint is that the output power should be less than or equal to the rated power : $P \leq 19.8 \mathrm{~kW}$.

As a consequence, for a steady reference wind speed $v_{r e}$, which varies from $v_{c i}$ to $v_{c o}$, the optimization problem is for- mulated as follows:

$$
\begin{array}{ll}
\text { minimize } & -P(\mathbf{x}, \mathbf{p}) \\
\text { over } & \mathbf{x}=\left[\gamma_{r} \gamma_{t}\right]^{T} \\
& \mathbf{p}=\left[\begin{array}{ll}
b \mathbf{c} r_{t} r_{r} \omega \rho v_{r e}
\end{array}\right] \\
\text { subject to } & P \leq 19.8 \mathrm{~kW} \\
& 0 \mathrm{deg} \leq \gamma_{r} \leq 35 \mathrm{deg} \\
& -5 \mathrm{deg} \leq \gamma_{t} \leq 15 \mathrm{deg}
\end{array}
$$

\subsection{Optimization Problem for the Blade With Pitch Control}

For the BPC, the decision variable is the pitch control angle: $\beta$. The distribution $(\boldsymbol{\gamma})$ of the pre-twist of the blade is shown in Fig. 5 (shifted by $-4.775 \mathrm{deg}$ ). The actual twist of the blade is calculated with Eqn. (26). The decision variable $\beta$ is bounded between $-5 \mathrm{deg}$ and $25 \mathrm{deg}$.

The performance function, the other design parameters and the constraint are the same as in the former optimization problem associated with the MB.

Then, for a steady reference wind speed, the optimization problem for the blade with pitch control is formulated as follows:

$$
\begin{array}{cc}
\text { minimize } & -P(x, \mathbf{p}) \\
\text { over } & x=\beta \\
& \mathbf{p}=\left[\boldsymbol{\gamma} b \mathbf{c} r_{t} r_{r} \omega \rho v_{r e}\right] \\
\text { subject to } & P \leq 19.8 \mathrm{~kW} \\
& -5 \mathrm{deg} \leq \beta \leq 25 \mathrm{deg}
\end{array}
$$

\subsection{Result Analysis \\ 5.3.1 Optimization Results}

The MATLAB fmincon function was used to solve optimization problems (28) and (29). Several starting points were used to come up with results, which are as close as possible to global optima.

Figure 12 shows the optimal performance of the $\mathrm{MB}$ and BPC at different wind speeds. Moreover, performance of the fixed pitch turbine, the Phase VI WT with a fixed pitch, are given.

The results show that the BPC can improve the power coefficients $C_{p}$ when wind speed is higher than $9 \mathrm{~m} / \mathrm{s}$. The main reason is that the FPB is stalled to maintain the output power when wind speed is higher than $12 \mathrm{~m} / \mathrm{s}$. Moreover, the results show that the produced power is higher with the MB than with BPC, except for some wind speed ranges. Since the actual twist angles of the MB are linear and the actual twist angles of the BPC are non-linear, it is understandable that the performance of BPC is better than MB for some wind speeds.

Table 2 shows the maximum power produced by wind turbines containing $\mathrm{FPB}, \mathrm{MB}$ and $\mathrm{BPC}$ for different wind speeds. Besides, the optimum twist angles $\gamma_{r}$ and $\gamma_{t}$ are given for the MB and the optimum pitch control angle $\beta$ is given for the BPC for the different wind speeds. The fixed pitch angle $\beta_{0}$ for the FPB is equal to $4.775 \mathrm{deg}$.

Figure 13 depicts the actual twist angles as a function of the blade radius for the three types of blade under study 

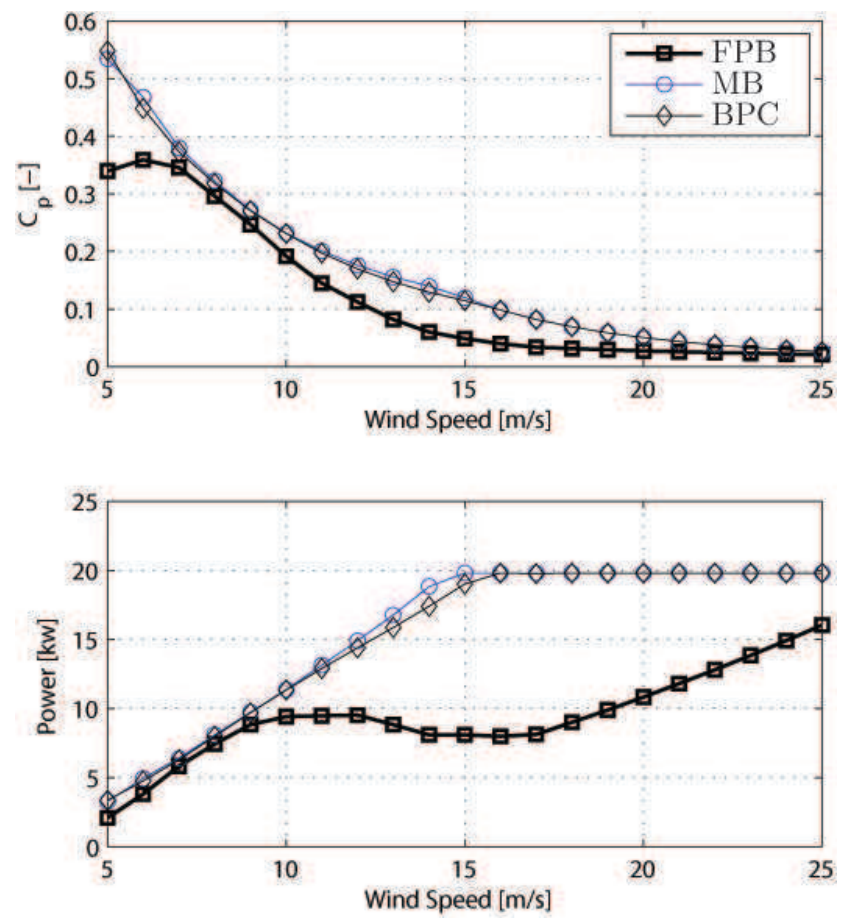

Fig. 12: Optimal performance of the MB and BPC at different wind speeds

and for a wind speed equal to $5 \mathrm{~m} / \mathrm{s}, 10 \mathrm{~m} / \mathrm{s}$ and $15 \mathrm{~m} / \mathrm{s}$, respectively.

\subsubsection{Comparing Annual Energy Production}

The Annual Energy Production (AEP) can be used as an index for the comparison of wind turbines. The AEP depends on the power curve of the wind turbine at hand and the variability of the wind.

The wind speed can be modeled by using a Weibull Distribution. The probability curve is usually defined by two parameters: the average wind speed $\bar{v}$ and the shape factor $k$ [18]. A simple model is chosen to assess the wind speed frequency. Indeed, a Rayleigh distribution is considered by setting the shape factor $k$ to 2 , i.e., $k=2$. Therefore, for a given average wind speed $\bar{v}$, the probability $p(v)$ for the wind speed to be equal to $v$ is obtained by the following formula:

$$
p(v)=\frac{\pi}{2} \frac{v}{\bar{v}^{2}} \exp \left(-\frac{\pi}{4}\left(\frac{v}{\bar{v}}\right)^{2}\right)
$$

Figure 14 illustrates the Rayleigh distributions of the wind speed for three average wind speeds, i.e., $\bar{v}=5 \mathrm{~m} / \mathrm{s}$, $\bar{v}=10 \mathrm{~m} / \mathrm{s}$ and $\bar{v}=15 \mathrm{~m} / \mathrm{s}$.

Table 3 and Fig. 15 show the annual energy production of the wind turbines as a function of the average wind speed and for the three types of blade. It appears that the AEP of the wind turbine containing morphing blades is $24.5 \%$ to $69.7 \%$ higher than the AEP of the wind turbine containing pitch fixed blades. Likewise, the AEP of the wind turbine contain-
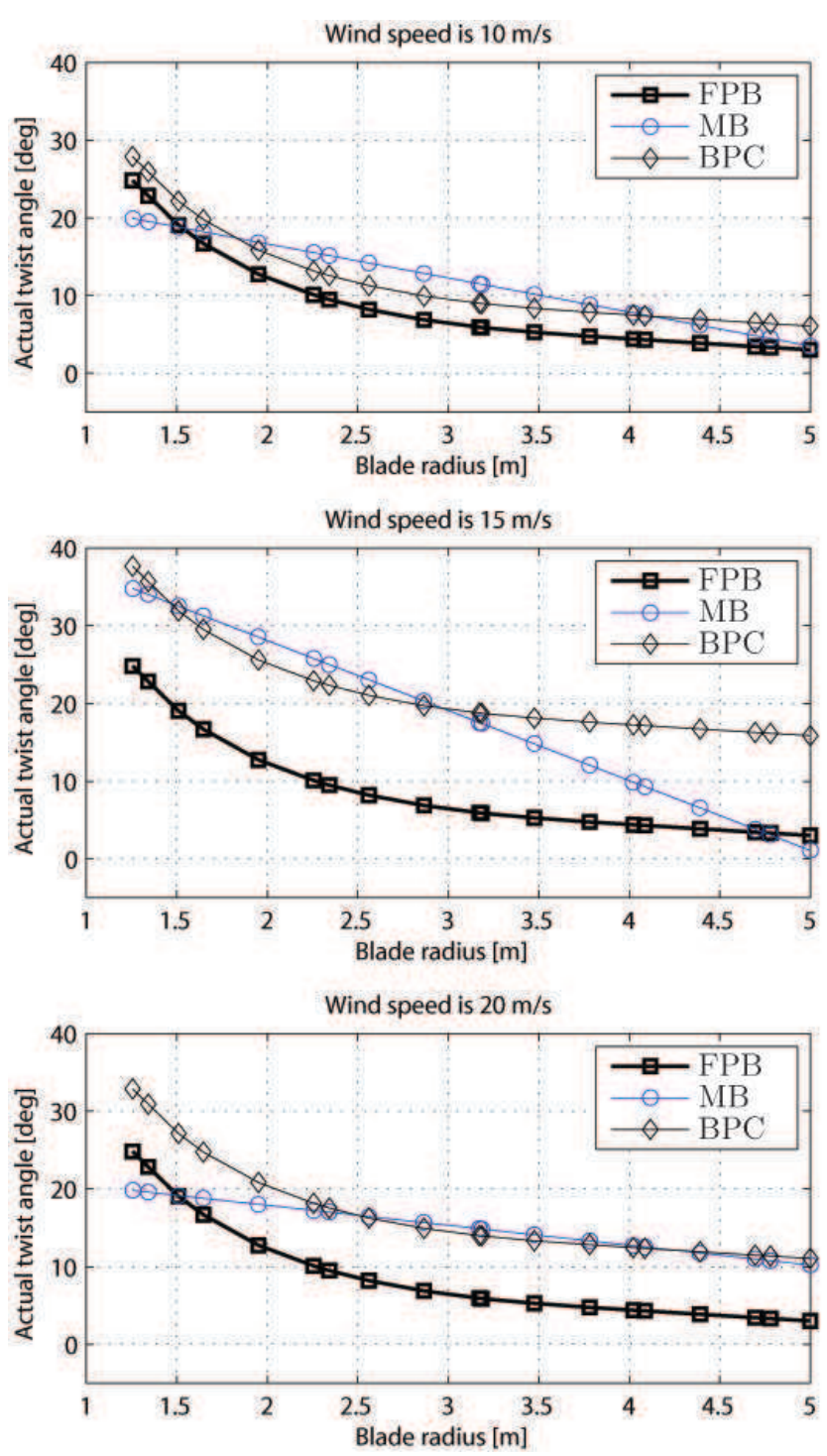

Fig. 13: Twist angle as a function of the blade radius for $v=5 \mathrm{~m} / \mathrm{s}, v=10 \mathrm{~m} / \mathrm{s}$ and $v=15 \mathrm{~m} / \mathrm{s}$

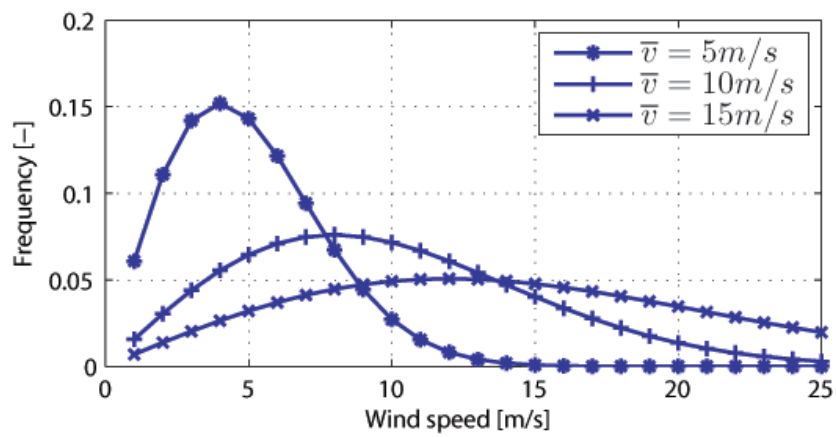

Fig. 14: Rayleigh distributions of the wind speed for three average wind speeds: $\bar{v}=5 \mathrm{~m} / \mathrm{s}, \bar{v}=10 \mathrm{~m} / \mathrm{s}$ and $\bar{v}=15 \mathrm{~m} / \mathrm{s}$ 
Table 2: Maximum power produced by wind turbines containing FPB, MB and BPC for different wind speeds

\begin{tabular}{|c|c|ccc|cc|}
\hline \hline & FPB & \multicolumn{3}{|c|}{ MB } & & \multicolumn{2}{|c|}{ BPC } \\
\cline { 2 - 7 }$v_{r e}$ & Power & Power & $\gamma_{r}$ & $\gamma_{t}$ & Power & $\beta$ \\
{$[m / s]$} & {$[k W]$} & {$[k W]$} & {$[d e g]$} & {$[\mathrm{deg}]$} & {$[k W]$} & {$[\mathrm{deg}]$} \\
\hline 5.0 & 2.08 & 3.28 & 2.24 & 0.302 & 3.36 & -0.296 \\
6.0 & 3.81 & 4.96 & 8.61 & -0.002 & 4.75 & 1.88 \\
7.0 & 5.82 & 6.41 & 15.6 & -1.78 & 6.28 & 2.5 \\
8.0 & 7.44 & 8.1 & 18.6 & -1.28 & 7.99 & 4.95 \\
9.0 & 8.83 & 9.74 & 20.8 & 0.933 & 9.69 & 6.47 \\
10.0 & 9.41 & 11.4 & 19.9 & 3.49 & 11.3 & 7.85 \\
11.0 & 9.48 & 13.1 & 27.0 & 3.24 & 12.9 & 9.39 \\
12.0 & 9.52 & 14.9 & 29.7 & 4.68 & 14.4 & 11.8 \\
13.0 & 8.84 & 16.8 & 32.2 & 5.9 & 15.9 & 13.7 \\
14.0 & 8.09 & 18.8 & 33.9 & 6.51 & 17.4 & 15.9 \\
15.0 & 8.1 & 19.8 & 34.8 & 1.07 & 19.0 & 17.6 \\
16.0 & 7.99 & 19.8 & 21.2 & 15.0 & 19.8 & 15.4 \\
17.0 & 8.12 & 19.8 & 21.3 & 9.26 & 19.8 & 13.6 \\
18.0 & 8.99 & 19.8 & 16.5 & 12.2 & 19.8 & 13.2 \\
19.0 & 9.89 & 19.8 & 11.5 & 14.1 & 19.8 & 12.8 \\
20.0 & 10.8 & 19.8 & 19.8 & 10.2 & 19.8 & 12.8 \\
21.0 & 11.8 & 19.8 & 28.1 & 8.93 & 19.8 & 12.6 \\
22.0 & 12.8 & 19.8 & 29.4 & 7.16 & 19.8 & 12.0 \\
23.0 & 13.8 & 19.8 & 16.0 & 10.0 & 19.8 & 10.4 \\
24.0 & 14.9 & 19.8 & 10.1 & 11.4 & 19.8 & 8.52 \\
25.0 & 16.0 & 19.8 & 13.1 & 6.15 & 19.8 & 7.09 \\
\hline \hline
\end{tabular}

ing blades with pitch control is $22.7 \%$ to $66.9 \%$ higher than the AEP of the wind turbine containing pitch fixed blades.

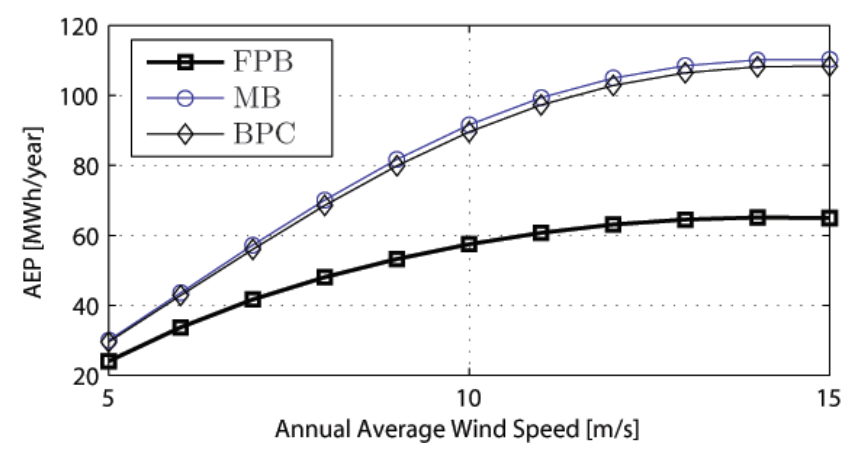

Fig. 15: AEP of the wind turbines as a function of the average wind speed
Table 3: AEP of the wind turbines as a function of the average wind speed

\begin{tabular}{|c|c|cc|cc|}
\hline \hline \multirow{2}{*}{$\bar{v}$} & FPB & \multicolumn{2}{|c|}{ MB } & \multicolumn{2}{c|}{ BPC } \\
\cline { 2 - 6 }$[m / s]$ & AEP & AEP & percentage & AEP & percentage \\
{$[M W h / y]$} & {$[M W h / y]$} & increase & {$[M W h / y]$} & increase \\
\hline 5.0 & 24.0 & 29.9 & 24.5 & 29.5 & $22.7 \%$ \\
6.0 & 33.7 & 43.6 & 29.4 & 42.8 & $27.1 \%$ \\
7.0 & 41.6 & 57.2 & 37.4 & 56.0 & $34.5 \%$ \\
8.0 & 48.0 & 70.1 & 45.9 & 68.6 & $42.7 \%$ \\
9.0 & 53.2 & 81.7 & 53.5 & 79.9 & $50.1 \%$ \\
10.0 & 57.5 & 91.6 & 59.4 & 89.6 & $55.9 \%$ \\
11.0 & 60.7 & 99.4 & 63.6 & 97.3 & $60.2 \%$ \\
12.0 & 63.1 & 105.0 & 66.4 & 103.0 & $63.1 \%$ \\
13.0 & 64.5 & 108.0 & 68.1 & 106.0 & $65.0 \%$ \\
14.0 & 65.1 & 110.0 & 69.2 & 108.0 & $66.2 \%$ \\
15.0 & 64.9 & 110.0 & 69.7 & 108.0 & $66.9 \%$ \\
\hline \hline
\end{tabular}

\section{Conclusions and Future Work}

A simplified morphing blade was introduced in this paper in order to improve the power capture ability of wind turbines. This morphing blade has a linear twist distribution along the span and its shape can be controlled by adjusting the root twist angle and the tip twist angle of the blade. A simulation model to compute the performance of wind turbines based on blade element momentum theory has been formulated and verified. Then, the optimization problems to maximize the produced power, associated with the morphing blades and the blades with pitch control were both formulated. At different wind speeds, there must be different adjustable parameters for the morphing blades and the blades with pitch control, which are decision variables of the optimization problems at hand. The optimal results show that the morphing blades provides better results than the blades with pitch control in terms of produced power. Under the assumption that at a given site, the annual average wind speed is known and the wind speed follows a Rayleigh distribution, the annual energy production of wind turbines was evaluated for three types of blade, namely, morphing blade, blade with pitch control and fixed pitch blade. For an annual average wind speed varying between $5 \mathrm{~m} / \mathrm{s}$ and $15 \mathrm{~m} / \mathrm{s}$, it turns out that the annual energy production of the wind turbine containing morphing blades is $24.5 \%$ to $69.7 \%$ higher than the annual energy production of the wind turbine containing pitch fixed blades. Likewise, the annual energy production of the wind turbine containing blades with pitch control is $22.7 \%$ to $66.9 \%$ higher than the annual energy production of the wind turbine containing pitch fixed blades. Finally, the detailed design of the inner structures of the proposed simplified morphing blade is part of the future work. 


\section{References}

[1] Lobitz, D., Veers, P., and Migliore, P. G., 1996. "Enhanced performance of HAWTs using adaptive blades". In Proceedings of 1996, ASME Wind Energy Symposium, pp. 41-45.

[2] Beyene, A., and Peffley, J., 2007. "A Morphing Blade for Wave and Wind Energy Conversion". OCEANS 2007 - Europe, June, pp. 1-6.

[3] Daynes, S., and Weaver, P. M., 2011. "A Morphing Wind Turbine Blade Control Surface". ASME Conference Proceedings, 2011, pp. 531-541.

[4] Barlas, T., 2010. "Review of state of the art in smart rotor control research for wind turbines". Progress in Aerospace Sciences, 46(1), Jan., pp. 1-27.

[5] Duran, S., 2005. "Computer aided design of horizontal axis wind turbine blades". Master's thesis, Middle East Technial University.

[6] Lanzafame, R., 2007. "Fluid dynamics wind turbine design: Critical analysis, optimization and application of BEM theory". Renewable energy, 32(14), Nov., pp. 2291-2305.

[7] Kulunk, E., and Yilmaz, N., 2009. "HAWT Rotor Design and Performance Analysis". ASME Conference Proceedings, 2009(48906), pp. 1019-1029.

[8] Tenguria, N., Mittal, N. D., and Ahmed, S., 2010. "Investigation of blade performance of horizontal axis wind turbine based on blade element momentum theory ( BEMT ) using NACA airfoils". International Journal of Engineering, Science and Technology, 2(12), pp. 2535.

[9] Dai, J., Hu, Y., Liu, D., and Long, X., 2011. “Aerodynamic loads calculation and analysis for large scale wind turbine based on combining BEM modified theory with dynamic stall model". Renewable Energy, 36(3), Mar., pp. 1095-1104.

[10] Hand, M. M., Simms, D. A., Fingersh, L., Jager, D., Cotrell, J., Schreck, S., and Larwood, S., 2001. Unsteady Aerodynamics Experiment Phase V: Test Configuration and Available Data Campaigns. Tech. Rep. December, NREL/TP-500-29955,National Renewable Energy Laboratory (NREL).

[11] Lanzafame, R., and Messina, M., 2010. "Horizontal axis wind turbine working at maximum power coefficient continuously". Renewable Energy, 35(1), Jan., pp. 301-306.

[12] J.F. Manwell, McGowan, J., and Rogers, A., 2002. "Wind Energy Explained Theory,Design and Application”. In Wind Energy Explained Theory,Design and Application Explained Theory,Design and Application. Wiley- Blackwell, ch. 3, pp. 83-139.

[13] Buhl, M. L., 2005. A New Empirical Relationship between Thrust Coefficient and Induction Factor for the Turbulent Windmill State. Tech. Rep. August, NREL/TP-500-36834,National Renewable Energy Laboratory (NREL).

[14] Lanzafame, R., and Messina, M., 2009. "Design and performance of a double-pitch wind turbine with non-twisted blades". Renewable Energy, 34(5), May, pp. 1413-1420.

[15] Ramsay, R. R., Hoffmann, M., and Gregorek, G., 1999. Effects of Grit Roughness and Pitch Oscillations on the S809 Airfoil: Airfoil Performance Report, Revised (12/99). Tech. Rep. December, National Renewable Energy Laboratory (NREL).

[16] Ramsay, R., Janiszewska, J., and Gregorek, G., 1996. Wind Tunnel Testing of Three S809 Aileron Configurations for use on Horizontal Axis Wind Turbines: Airfoil Performance Report. Tech. Rep. July, National Renewable Energy Laboratory (NREL).

[17] Merabet, A., Thongam, J., and Gu, J., 2011. "Torque and Pitch Angle Control for Variable Speed Wind Turbines in All Operating Regimes". Environment and Electrical Engineering (EEEIC), 2011 10th International Conference on, 1(2), pp. 1-5.

[18] Aldo Vieira da Rosa, 2009. "Fundamentals of Renewable Energy Processes". No. March 1945. ch. Chapter 15, pp. 723-797. 